\title{
Sector coupling \\ of renewable energy in an experimental setting
}

\author{
Findings from a smart energy pilot project in Austria
}

Michael Ornetzeder, Institute of Technology Assessment, Austrian Academy of Sciences, Apostelgasse 23, 1030 Vienna (michael.ornetzeder@oeaw.ac.at)
(D) https://orcid.org/0000-0003-3956-7090
Tanja Sinozic, Institute of Technology Assessment, Austrian Academy of Sciences (tanja.sinozic@oeaw.ac.at) (D) https://orcid.org/0000-0002-1070-1340

The integration of previously unconnected sectors of the energy system is considered one of the most important strategies for reducing $\mathrm{CO}_{2}$ emissions. Many studies on technological innovations that deal with the transition to a sustainable energy system focus on innovation niches as a favorable environment within which new solutions can be tested and made ready for the market. This paper examines how protection in such a niche, in combination with organizational path dependency, supports the integration of renewable energy in residential buildings. The results presented are based on a case study on the integration of the electricity, heat, and gas sectors in a housing pilot project, in which local energy needs are met and electricity is fed into the grid in a flexible way. Our findings indicate that favorable conditions for inter-sectoral innovation can be achieved through niche protection, complemented by path dependency in organizational routines and culture.

\section{Sektorkopplung erneuerbarer Energien in einer experimentellen Umgebung}

Erkenntnisse aus einem Pilotprojekt für intelligente Energiegebäude in Österreich

Die Integration von bisher nicht miteinander verbundenen Sektoren des Energiesystems gilt als eine der wichtigsten Strategien zur Reduktion von $\mathrm{CO}_{2}$-Emissionen. Viele Studien zu technischen Innovationen, die sich mit dem Übergang zu einem nachhaltigen Energiesystem befassen, konzentrieren sich auf Innovationsnischen als ein förderliches Umfeld, in dem neue Lösungen getestet und zur Marktreife gebracht werden können. Im vorliegenden Beitrag wird untersucht, wie der Schutz in einer solchen Nische in Kombination mit bestehenden Pfadabhängigkeiten die Integration erneuerbarer Energien bei Wohngebäuden be-

This is an article distributed under the terms of the Creative Commons Attribution License CCBY 4.0 (https://creativecommons.org/licenses/by/4.0/)

https://doi.org/10.14512/tatup.29.2.38

Submitted: 14. 02.2020. Peer reviewed. Accepted: 15. 05.2020 günstigt. Die Ergebnisse basieren auf einer Fallstudie zur Integration der Sektoren Strom, Wärme und Gas in einem Pilotprojekt, bei dem der lokale Energiebedarf gedeckt und flexibel Strom in das Netz einspeist wird. Unsere Ergebnisse deuten darauf hin, dass förderliche Bedingungen für intersektorale Innovation durch Schutz in der Nische, ergänzt durch Pfadabhängigkeit in Organisationsroutinen und Organisationskultur, gewährleistet werden können.

Keywords: sectoral integration, energy transitions, smart grids, pilot and demonstration projects (PDPS), green buildings

\section{Introduction}

A stronger integration of different sectors of the energy system is seen as one of the key strategies to support the transformation towards greater sustainability. The underlying rationale behind the concept is to move away from sector-specific approaches that only consider solutions within sectors, and instead adopt a more holistic approach to all sectors, allowing for energy-efficient and more cost-effective overall configurations. There are numerous options in which technical applications from different sectors can be combined to achieve significantly higher efficiency levels (BDEW 2017). The term smart energy system is used in the literature when referring to energy concepts in which various forms of energy and sectors are combined with computing-based control technology to create increasingly efficient solutions (Lund et al. 2017).

However, several regulatory, organisational, economic, and technical problems limit the widespread implementation of such solutions. In addition, approaches to the integration of different sectors often lead to greater complexity and thus to new and difficult-to-estimate risks in practice (Büscher 2018). 
In this paper, we present a case study from Austria in which the heat, gas and electricity sectors were coupled. The underlying empirical investigation was carried out in 2016 and 2017 as part of the European project MATCH ${ }^{1}$. During two site visits, a total of seven qualitative interviews were conducted: with the project manager as well as two people involved in the project, and with three residents of the housing estate. The interviews were transcribed and analysed using content analysis software. In addition, written material (reports, project descriptions) was included in the case study. for the entire energy system as well as for underlying individual sub-systems.

However, in practice sectoral coupling combined with renewable energy sources faces several unresolved problems. Wietschel et al. (2018) discuss a number of issues for the German context that need to be addressed if integrated solutions are to become more widespread in the energy system. These include macro and sectoral level issues such as regulatory and legal aspects, economic considerations of costs and revenue opportunities, IT issues, supply-side and consumption-side potentials,

\section{The coupling of different sectors of the energy system usually leads to greater complexity and thus brings about new and difficult-to-estimate risks.}

In the text below we demonstrate and discuss the results of this study. We examine why the technologically advanced pilot project could be realised and how the project was perceived by the end users. Before discussing the case study in more detail, the following section presents the theoretical approaches through which the findings are viewed and analysed.

\section{Innovation, strategic niches, and path dependencies in sector coupling of renewable energy}

A definition of innovation in sector coupling of renewables, which can be considered to align most closely with the goals of energy transition strategies in the EU, most notably in Germany, is the one provided by the German Association of Energy and Water Industries (BDEW): "the energy engineering and energy economy of the connection of electricity, heat, mobility and industrial processes, as well as their infrastructures, with the aim of decarbonisation, while simultaneously increasing the flexibility of energy use in the sectors of industry and commercial/trade, households and transport under the premises of profitability, sustainability and security of supply" (BDEW 2017). Intersectoral coupling intends to achieve several synergies in energy production and consumption. According to Lund et al. (2017), these include, amongst others, much better use of waste heat, more flexible CHP production, or better balancing of the electricity grids and thus greater integration of renewable energies. The coupling of sectors that have, up until now, mostly existed independently is expected to bring advantages

1 The project MATCH (Markets, Actors and Technologies - A comparative study of smart grid solutions) was funded by the ERA-Net Smart Energy Systems programme and involved partners from Austria, Denmark, and Norway, and ran from February 2016 to October 2018. Project website: https://www.match-project.eu/. and practical challenges for the implementation as well as social science aspects such as micro-level acceptance of specific integrated solutions.

History has shown that the coupling of different sectors of the energy system usually leads to greater complexity and thus brings about new and difficult-to-estimate risks. Büscher and Sumpf (2015) argue that smart technology and new business models will create socio-technical problems as they rely on structural coupling of technology and communication. This makes it difficult to predict and control these systems, jeopardises the reliability of output, and causes a lack of transparency. Moreover, the solutions to these problems change over time and differ across contexts so that all solutions are indeed temporary and simultaneously create new problems (Büscher 2018). However, under the current regulatory framework operators of smart energy systems are also exposed to certain risks, for example with regard to their actual ability to make a profit (Leisen et al. 2019). This situation could also be found in the present case where the coupling of several energy sectors was realised in a strategic niche context.

One of the most prominent frameworks used to understand the socio-technical factors and processes required for system-wide sustainable energy transitions that are reinforced by developments at the local, project and individual levels, is strategic niche management (SNM) (Schot and Geels 2008). The SNM approach suggests that innovation processes that can potentially lead to regime-wide transformations can be enabled through experimentation and mutual alignment of technology design, user practices, and regulatory structures in technological niches (Schot 1992; Rip and Kemp 1998). Niches are spaces protected from market competition (similar to the infant industry argument in international trade) where firms and industries develop variations which do not yet fit the existing selection environment. The probability of being competitive (over time) is increased because initial trial-and-error processes are confined 
to a scale where the cost of errors is both relatively predictable and accounted for.

The premise of transformation in technological niches is partially determined by diversity in the sense that different actors are present, and also that they differ from who was previously part of the group (Sengers et al. 2019). For example, the seminal approach to the technological regime states that stability and continuation can be achieved through collectively shared cognitive routines (Nelson and Winter 1982; Dosi 1982) which are aligned with those of engineers and investors in the dominant trajectory. The niche approach emphasises the importance of alignment of different actors, structures and processes such as scientists, policymakers, industry, infrastructures, and cultural significance (Kemp 1994).

The majority of empirical cases on which niche concepts have been tested are engineering research and development (R \& D) contexts such as experiments or pilot and demonstration projects (PDPs) (Hoogma et al. 2002) which are part of a national innovation strategy. PDPs are required for learning about a new technology at corporate level (Rosenberg and Steinmueller 2013), and indeed most studies conclude that this is the main outcome of this type of setting (Brown and Vergragt 2008; Frishammar et al. 2015), with the guiding vision being competitiveness, job creation, and growth at national level. Learning from PDPs can be categorised into different types, such as, for example, technical learning effects, organisational learning effects, policy learning effects, and market learning effects as categorised by Bossink (2017) who found technical learning to be the most important reason for organisations to invest in PDPs in sustainable energy.

More recently however, PDPs have taken on different roles in the innovation system and are also being framed as policies for sustainability transitions (Geels and Schot 2007). This shift can be likened to strategically placed vehicles to achieve not only traditional policy goals of employment and growth, but also assist with integrating broader societal and environmental values into technology development (Huguenin and Jeannerat 2017).

National innovation system strategies targeting innovation in complex technologies such as renewables integration in energy systems rely upon systems integration capabilities which are highly path-dependent (Rycroft and Kash 2002). These technological capabilities integrate diverse scientific and engineering knowledge bases that are required for complex product, process and systems innovation. Integrating and combining different technologies at micro level depends heavily upon their availability at the local level (Hansen 1992; Maskell and Malmberg 1999).

Capabilities and routines at corporate level directly influence how a company carries out its production processes, but most importantly how innovative it is. According to Coombs and Hull (1998), three aspects of the company can be used to define its path dependence: (1) its "technology as hardware" which includes physical artefacts such as, for example, products, machinery, equipment, and software; (2) the company's "knowledge base", and (3) the company's "organisational routines" on which it depends to conduct its regular business (Coombs and Hull 1998, p 243). Knowledge bases can be defined in various ways, but Hodgson (1993), cited in Combs and Hull (1998), emphasises "corporate culture" and "competencies" to "mould the individual perceptions, preferences, abilities and actions of its personnel". Trust and loyalty are the outcomes of this capacity as well as cultural institutional aspects such as practices and habitual ways of thinking. Regarding the third aspect, corporate path dependency depends upon what the company does in practice, for example specific "knowledge management practices" (Coombs and Hull 1998, p. 244). Such practices can, for example, be formal or informal, paper-based or electronic, people- or system-driven, focused on knowledge management or peripheral to it.

The following case study applies these perspectives when examining favourable conditions for the coupling of different energy sectors in a highly ambitious pilot project in Salzburg, Austria.

\section{Renewables integration in a smart energy system pilot project in Austria}

The case study analyses a local smart energy system (Lund et al. 2017) that was realised as a pilot project in a new residential building complex. The project combines smart electricity, thermal and gas grids with thermal storage to harness synergies between the different sectors. The aim of the configuration is to use the housing complex as an active element in the electricity grid and thus make the grid more flexible without compromising the needs of the residents. The applied smart energy system works according to the following basic "logic": the building consumes electricity when the price is low (which is when the share of renewable energies in the grid is large) and it produces electricity when the feed-in tariff is high. The required flexibility is mainly provided by on-site heat storage.

The pilot project, later called Rosa Zukunft ${ }^{2}$, started as a nationally funded research project under the umbrella of the smart grids model region Salzburg in 2011. It was conducted by a consortium including the local energy supplier (Salzburg AG), a non-profit housing developer (Salzburg Wohnbau), and a main technology provider (Siemens Austria) together with several research institutes (Austrian Institute of Technology, CURE, Fichtner, and the Vienna Technical University). This team developed the technical concept and related planning requirements for the project. Together with additional housing developers and a company for social services as well as an engineering office, eight residential buildings with 129 apartments were planned and constructed almost simultaneously to launch-

2 The term Rosa Zukunft combines a reference to the location of the residential building complex (Rosa-Hoffmann-Straße [street name] in Salzburg) with the seminal orientation of the technical concept. 
ing the research project. Construction was started in 2012 and the first residents moved in in late 2013. The city of Salzburg supported the project by providing attractive framework conditions such as housing subsidies for the installation of photovoltaic (PV) systems.

As a pilot project, Rosa Zukunft had wide-ranging technical and social ambitions. In addition to the smart energy system solution which is at the centre of this paper, a one-year demand-response trial was conducted with selected households (Salzburg AG 2015). Furthermore, it was planned to provide electric vehicles to some residents and to have these integrated into the energy concept as controllable load. However, this part of the project could not be realised because of a lack of demand.

The smart energy system that was implemented consists of a number of different elements: technologies to produce and consume electricity on-site, technologies to store and distribute energy in the form of heat, smart control technologies to run the system as automatically as possible, and connections to electricity, gas and district heating infrastructures. The entire smart energy system is owned and operated by the energy supplier (Salzburg AG), and most of the essential technical equipment is located in one of the eight residential buildings of the complex ("technical room").

Broadly speaking, in practice this system works as follows: the energy supplier creates a simulated price curve which is updated daily. It is made up of assumed grid and electricity costs (based on the actual stock exchange price). The information is transmitted daily to the control unit of the local system and used to control the plant the following day. Based on this and additional information about the expected energy needs of the build- both economically advantageous and useful to the grid, e.g. to support the integration of flexible renewable generation facilities throughout the grid.

The 129 apartments in the complex and the communal facilities are supplied with thermal energy for hot water and heating needs through a micro grid. To guarantee the energy supply to consumers, the pilot project's micro grid is additionally connected to the district heating network (backup). The PV panels installed on the roofs of the residential complex are also operated by the project owner but are not integrated into the smart energy system. The electricity produced is simply fed into the grid.

According to the interviewees involved in the project, the system has proven to be effective in practice. The main objectives of the project were achieved: the heat supply to households is working with great reliability except for a few problems during the start-up phase. Only economic efficiency is suboptimal because of backup facilities and oversized technical elements. Compared with a conventional energy system, however, this case exhibits a number of specific issues.

It is evident that such a project involves higher levels of technical, legal, financial, and organisational complexity. The planning and building of the applied system were highly dependent on extensive use of computers and electrical engineering, mainly because of the nature of the equipment and the sophisticated modelling and programming that is involved in making such a system work well. It took considerable effort to calculate not only the building complex's specific energy needs and at what times energy was required, but also to design the corresponding size of the energy production and storage units. During the construction phase, the project needed significantly more effort

\section{Synergies across the sectors of smart electricity, thermal and gas grids together with thermal storage can make the housing complex an active element in the electricity grid.}

ing, the system can work in two modes: either in the "electricity production mode" or in the "electricity consumption mode". In the former, electricity is generated on-site using a CHP plant that runs on biogas. The electricity is supplied to the public grid, and the waste heat from the plant is used to heat water in a large storage tank $\left(90 \mathrm{~m}^{3}, 18 \mathrm{~m}\right.$ tall) which is integrated into one of the buildings. In the other mode, when electricity is to be consumed because of favourable stock exchange prices, a heat pump is activated. It uses groundwater from six drill holes located 200 below the ground to produce heat energy which is also stored in the large on-site tank. In both operating modes, the electricity and heat sectors are coupled. In the case of electricity production, the gas sector is also added. The primary goal of the configuration is to make heat production in the housing complex in coordinating and convincing the numerous partners from different areas and disciplines than traditional projects of this size. Conventional construction projects are usually developed with strong pressures regarding time and cost. Additional requirements, such as those imposed by a research project, tend to exacerbate this situation. The smart energy system also requires new technologies (e.g. the central control unit, an in-house development of Siemens AG) and new combinations of existing technologies from which risks and unforeseeable situations must be expected (Luhmann 1991). Although the project was financially supported by the public sector, the project owner also took financial risks. Extraordinary investment costs are offset by possible profits from the sale of heat and electricity. And of course, there was uncertainty in the beginning as to how users would re- 
act. In our interviews, for example, some residents complained about what they perceived to be the energy supplier's monopoly position. In fact, the monopoly situation exists only regarding the heat supply. However, because of joint invoicing (Salzburg AG provides heat, electricity, water, and telecommunication services), some residents got the impression that they could only purchase electricity from the project owner, which was not the case.

Building on the results and experience gained from the pilot project, the project owner has now implemented several similar projects. However, these projects have a simpler design, the storage tanks are significantly smaller, there are no heat pumps, and the systems are not controlled by a simulated price curve (which is also no longer used in the pilot project). Although these follow-up projects combine different forms of energy, they are not designed to balance the electricity grid because there is currently no functioning market for this in Austria. The aim of these projects is to achieve optimal economic performance under current market conditions.

\section{Discussion}

The smart energy system implemented in the course of the pilot project involved the coupling of different sectors in order to create an efficient and renewable solution. However, the implemented solution is limited in both size and impact. According to the project management, the objective was to build a functioning pilot plant and thus gain hands-on experience. The case study shows that even small, locally bounded smart energy systems are
Salzburg AG, which has been working on technical smart grid research projects since 2004, was awarded the national programme contract for the Smart Grids Model Region Salzburg together with two partners (Siemens AG and Salzburg Wohnbau) as part of the New Energies 2020 national funding framework. New Energies 2020 was one of several programmes of the Climate and Energy Fund which was created two years earlier to support the federal government in implementing the Austrian Climate Strategy (Klima- und Energiefonds 2010). Within the framework of the designated model region, knowledge from previous projects was consolidated, providing the basis for the planning and implementation of several other pilot and demonstration projects. The overall objective of the model region was to conduct comprehensive research into the various options that smart grid technology potentially offers for the transition of the energy system (bmvit 2010).

The status as a model region helped to provide access to research funding and reinforced the normative orientation of the projects aimed at developing technologies for a decarbonised energy economy (Klima- und Energiefonds 2010). However, this strong research orientation resulted in designing a project for potential future framework conditions (e.g. clear price signals from the electricity market) and favoured a solution based on technical feasibility rather than on economic considerations (e.g. heat pump and CHP, oversized storage tank, district heating connection). A further consequence of the activities conducted over several years within the model region was the establishment of a strong network of actors consisting of energy companies, technology providers, research institutions, housing developers, and contractors. The pilot project Rosa Zukunft could be accom-

\section{Even small, locally bounded smart energy systems are associated with high demands on planning and implementation as well as with new risks.}

associated with high demands on planning and implementation as well as with new risks. Subsequently, we will discuss two specific circumstances found at the project level in this example of sector coupling, which were important for the implementation.

The first condition results from the fact that this was a publicly funded pilot project (Salzburg AG 2015). Pilot projects usually take place in a "protected space" (Smith and Raven 2012) that supports broad experimentation with new solutions. This is essential because technologies in early phases of development require strategic support to protect them against market forces and allow for the improvement of performance, price, and infrastructures because of their immaturity (Raven et al. 2016). This was true for this pilot project as Rosa Zukunft was one of three major pilot projects part of a nationally funded smart grid initiative (Salzburg AG 2015). plished not least because most of the participating partners had already been involved in earlier projects, allowing them to jointly acquire knowledge and build mutual trust (Salzburg AG 2015).

The status as a model region and the associated research funds were undoubtedly of central importance for the pilot project. However, the protected space was also created as a result of additional factors. The research activities of various Salzburg AG departments were strongly promoted and supported by the management, the national energy regulator approved the use of the simulated price curve to control the plant, and the city and region of Salzburg provided helpful political support.

In addition, the project benefited from existing internal company path dependencies. This aspect is closely related to the history and corporate culture of the project owner and leading player of the model region activities, the Salzburg AG. Not only 
is Salzburg AG the main regional energy provider, it is also a multi-utility firm covering the fields of electricity supply, natural gas, district heating, water, telecommunications, and transport. Today's Salzburg AG was formed in the year 2000 from merging two different companies, the municipal utilities of Salzburg and the former provincial energy supplier (SAFE). Both predecessors have existed for more than one hundred years. To this day, Salzburg AG is majority-owned by the city and province of Salzburg (Eymannsberger and Kurtz 2017). With this particular history, Salzburg AG was well suited to deal with smart grids in the early 2000s. The associated vision of linking various sectors and business areas has long been part of the firm's identity and culture.

As a result of market liberalisation in the energy sector, the network operator Salzburg Netz GmbH was founded in 2006. This company operates the distribution networks for electricity and gas in the province of Salzburg and is a $100 \%$ subsidiary of Salzburg AG (Eymannsberger and Kurtz 2017). In our case study we could observe that the separation of energy provider and network operator was thus only implemented on paper. The two companies share common headquarters and there were almost no institutional barriers for the cooperation of the two companies within the smart grids model region. This form of "easy unbundling" also helped with the implementation of the pilot project. An existing common organisational structure, familiar internal company processes, a common identity, and the physical proximity of the necessary specialist departments contributed to the management of amplified requirements during the set-up of the local smart energy system.

\section{Conclusion}

This pilot project is one of those examples where the coupling of different sectors in order to increase the efficiency and use of renewable energies has been implemented to a very high degree, especially when compared internationally. However, the project is local and limited in size and impact. Despite these limitations, the implementation of the project was associated with a number of uncertainties and risks as well as additional difficulties. The project required higher levels of technical, organisational, legal, and financial complexity. Extensive simulations and model calculations were necessary during the planning stage, considerably more actors were involved in the implementation than in a conventional project, legal exceptions were necessary for the use of the simulated price curve, and because of a lack of experience and the non-existent market for demand response services, there were also financial risks for the project operator.

We have shown how the pilot project works in practice, which sectors are connected in what ways and with which objectives. We outlined the history of the project and found that both a protected space in a specially created innovation niche and long-standing path dependencies contributed to the characteristics of the chosen approach of the pilot project and its success- ful implementation. This also allowed potential technical, economic, and organisational risks to be managed effectively. However, on the end user side, criticism was expressed about the resulting monopolistic situation associated with this solution. The fact that the experience gained in the pilot project was only partially implemented in subsequent activities of the project operator is mainly the result of a lack of a favourable economic and legal framework for such projects.

\section{References}

BDEW - Bundesverband der Energie- und Wasserwirtschaft e. V. (2017): Positionspapier. 10 Thesen zur Sektorkopplung. Available online at https://www.bdew. de/service/stellungnahmen/10-thesen-sektorkopplung/, last accessed on 27.01.2020

bmvit - Austrian Federal Ministry of Transport, Innovation and Technology (ed.) (2010): Smart grids showcase region: Salzburg. Integrated infrastructure in Salzburg. Vienna: Austrian Federal Ministry of Transport, Innovation and Technology.

Bossink, Bart (2017): Demonstrating sustainable energy. A review based model of sustainable energy demonstration projects. In: Renewable and Sustainable Energy Reviews 77, pp. 1349-1362. D0I: 10.1016/j.rser.2017.02.002.

Brown, Halina; Vergragt, Philip (2008): Bounded socio-technical experiments as agents of systemic change. The case of a zero-energy residential building. In: Technological Forecasting and Social Change 75 (1), pp. 107-130.

Büscher, Christian; Sumpf, Patrick (2015): "Trust" and "confidence" as socio-technical problems in the transformation of energy systems. In: Energy, Sustainability and Society 5 (1), p. 13. DOI: 10.1186/s13705-015-0063-7.

Büscher, Christian (2018): Framing energy as a sociotechnical problem of control, change, and action. In: Christian Büscher, Jens Schippl and Patrick Sumpf (eds.): Energy as a sociotechnical problem. An interdisciplinary perspective on control, change and action in energy transitions. London: Routledge, pp. 14-38.

Coombs, Rod; Hull, Richard (1998): 'Knowledge management practices' and path-dependency in innovation. In: Research Policy 27 (3), pp. 237-253.

Dosi, Giovanni (1982): Technological paradigms and technological trajectories. A suggested interpretation of the determinants and directions of technological change. In: Research Policy 11 (3), pp. 147-62.

Eymannsberger, Helmut; Kurtz, Klemens (2017): Salzburg AG. Regionalwirtschaftliche Bedeutung und Wertschöpfungsanalyse. Available online at https://www.salzburg-ag.at/content/dam/web18/dokumente/presse/ Wertschoepfungsstudie_Salzburg\%20AG.pdf, last accessed on 12.05.2020.

Frishammar, Johan; Söderholm, Patrik; Bäckström, Kristoffer; Hellsmark, Hans; Ylinenpää, Håkan (2015): The role of pilot and demonstration plants in technological development: synthesis and directions for future research. In: Technology Analysis \& Strategic Management 27 (1), pp. 1-18.

Schot, Johan; Geels, Frank (2007): Niches in evolutionary theories of technical change. In: Journal of Evolutionary Economics 17 (5), pp.605-622. DOI: 10.1007/s00191-007-0057-5.

Hansen, Niles (1992): Competition, trust, and reciprocity in the development of innovative regional milieu. In: Papers in Regional Science 71 (2), pp. 101-102.

Hodgson, Geoffrey (1993): Corporate culture and the nature of the firm. In: Judge Institute of Management Studies Working Paper No. 14, 1993-94. Cambridge: University of Cambridge. 
Hoogma, Remco; Kemp, René; Schot, Johan; Truffer, Bernard (2002): Experimenting for sustainable transport. The approach of strategic niche management. London: Spon Press.

Huguenin, Ariane; Jeannerat, Hugues (2017): Creating change through pilot and demonstration projects. Towards a valuation policy approach. In: Research Policy 46 (3), pp. 624-635.

Kemp, Rene (1994): Technology and the transition to environmental sustainability, In: Futures 26 (10), pp. 1023-1046.

Klima- und Energiefonds (2010): Geschäftsbericht 2009. Available online at https://www.klimafonds.gv.at/wp-content/uploads/sites/6/ Geschaeftsbericht2009.pdf, last accessed on 12.05.2020.

Leisen, Robin; Steffen, Bjarne; Weber, Christoph (2019): Regulatory risk and the resilience of new sustainable business models in the energy sector. In: Journal of Cleaner Production 219, pp. 865-878.

Luhmann, Niklas (1991): Soziologie des Risikos. Berlin: de Gruyter.

Lund, Henri; Østergaard, Poul Alberg; Connolly, David; Mathiesen, Brian Vad (2017): Smart energy and smart energy systems. In: Energy 137, pp. 556-565.

Maskell, Peter; Malmberg, Anders (1999): Localized learning and industrial competitiveness. In: Cambridge Journal of Economics 23 (2), pp. 167-185. DOI: 10.1093/cje/23.2.167.

Nelson, Richard; Winter, Sidney (1982): An evolutionary theory of economic change. Cambridge: Harvard University Press.

Raven, Rob; Kern, Florian; Verhees, Bram; Smith, Adrian (2016): Niche construction and empowerment through socio-political work. A meta-analysis of six low-carbon technology areas. In: Environmental Innovation and Societal Transitions 18, pp. 164-180.

Schot, Johan (1992): Constructive technology assessment and technology and technology dynamics. The case of clean technologies. In: Science, Technology, \& Human Values 17 (1), pp. 36-56.

Rip, Arie; Kemp, René (1998): Technological change. In: Steve Rayner and Elizabeth Malone (eds.): Human choice and climate change. Vol. 2. Columbus: Battelle Press, pp. 327-399.

Rosenberg, Nathan; Steinmueller, W. Edward (2013): Engineering knowledge. In: Industrial and Corporate Change 22 (5), pp. 1129-1158.

Rycroft, Robert; Kash, Don (2002): Path dependence in the innovation of complex technologies. In: Technology Analysis \& Strategic Management 14 (1), pp. 21-35.

Salzburg AG (ed.) (2015): Resultate \& Erkenntnisse aus der Smart Grids Region Salzburg. Zusammenfassung. Available online at http://www.smartgrids salzburg.at/content/dam/websites/smartgrids/Downloads/SG_ Erkenntnisbericht.pdf, last accessed on 12.05.2020.

Schot, Johan; Geels, Frank (2008): Strategic niche management and sustainable innovation journeys. Theory, findings, research agenda, and policy. In: Technology Analysis \& Strategic Management 20 (5), pp. 537-554.

Sengers, Frans; Wieczorek, Anna; Raven, Rob (2019): Experimenting for sustainability transitions. A systematic literature review. In: Technological Forecasting and Social Change 145, pp. 153-164.

Smith, Adrian; Raven, Rob (2012): What is protective space? Reconsidering niches in transitions to sustainability. In: Research Policy 41, pp. 1025-1036.

Wietschel, Martin et al. (2018): Sektorkopplung. Definition, Chancen und Herausforderungen. Diskussionspapier im Rahmen des Kopernikus-Projekt „Systemintegration“. Karlsruhe: Fraunhofer ISI.

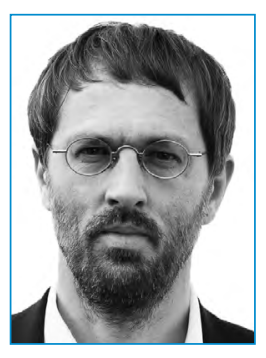

PRIV.-DOZ.MAG.DR . MICHAEL ORNETZEDER

is a Senior Researcher at the Institute of Technology Assessment (ITA), Austrian Academy of Sciences. He has PhD and post-doc level research and teaching experience in technology assessment and science and technology studies, with a particular focus on energy transitions, sustainable energy technologies, user innovation, and social learning.

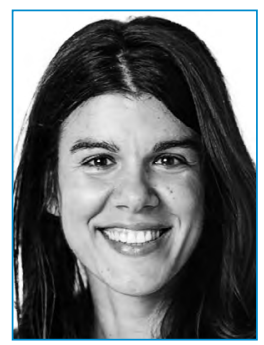

\section{DR. TANJA SINOZIC}

is a Senior Researcher at the Institute of Technology Assessment (ITA), Austrian Academy of Sciences. Since joining the ITA in 2015, she has been working on energy transitions in Austrian regions. She was originally trained in economics and regional planning before obtaining a PhD in Science Policy at the Science Policy Research Unit (SPRU), University of Sussex. 